\title{
KUD773, a phenylthiazole derivative, displays anticancer activity in human hormone-refractory prostate cancers through inhibition of tubulin polymerization and anti-Aurora A activity
}

\author{
Chia-Chun Yu', Shih-Ping Liu², Jui-Ling Hsu', John TA Hsu ${ }^{3}$, Konstantin V Kudryavtsev ${ }^{4,5^{*}}$ and Jih-Hwa Guh ${ }^{1 *}$
}

\begin{abstract}
Background: Hormone-refractory prostate cancer (HRPC), which is resistant to hormone therapy, is a major obstacle in clinical treatment. An approach to inhibit HRPC growth and ultimately to kill cancers is highly demanded.

Results: KUD773 induced the anti-proliferative effect and subsequent apoptosis in PC-3 and DU-145 (two HRPC cell lines); whereas, it showed less active in normal prostate cells. Further examination showed that KUD773 inhibited tubulin polymerization and induced an increase of mitotic phosphoproteins and polo-like kinase 1 (PLK1) phosphorylation, indicating a mitotic arrest of the cell cycle through an anti-tubulin action. The kinase assay demonstrated that KUD773 inhibited Aurora A activity. KUD773 induced an increase of Cdk1 phosphorylation at $\operatorname{Th}^{161}$ (a stimulatory phosphorylation site) and a decrease of phosphorylation at $\mathrm{Tyr}^{15}$ (an inhibitory phosphorylation site), suggesting the activation of Cdk1. The data were substantiated by an up-regulation of cyclin B1 (a Cdk1 partner). Furthermore, KUD773 induced the phosphorylation and subsequent down-regulation of Bcl-2 and activation of caspase cascades.

Conclusions: The data suggest that KUD773 induces apoptotic signaling in a sequential manner. It inhibits tubulin polymerization associated with an anti-Aurora A activity, leading to Cdk1 activation and mitotic arrest of the cell cycle that in turn induces $\mathrm{BCl}-2$ degradation and a subsequent caspase activation in HRPCs.
\end{abstract}

Keywords: Hormone-refractory prostate cancer, Phenylthiazole derivative, Tubulin depolymerization, Aurora A kinase, Mitochondria-involved apoptosis

\section{Background}

The anticancer agents that act on different cellular targets may result in an arrest of the cell cycle at particular phase. Tubulin-targeting agents inhibit normal function of mitotic spindle, leading to a halt of the cell cycle at mitotic phase and a subsequent cell death [1-3]. Currently, tubulin-targeting agents have been successfully used in cancer chemotherapy against several types of cancers, including breast cancer, ovarian cancer and hormonerefractory prostate cancer (HRPC) $[1,4,5]$. However, the toxicities, such as peripheral neuropathy, myelosuppression

\footnotetext{
* Correspondence: kudr@med.chem.msu.ru; jhguh@ntu.edu.tw ${ }^{4}$ Department of Medicinal Chemistry, Faculty of Chemistry, M.V. Lomonosov Moscow State University, Moscow, Russian Federation

${ }^{1}$ School of Pharmacy, National Taiwan University, Taipei, Taiwan

Full list of author information is available at the end of the article
}

and neutropenia, limit the effectiveness of tubulintargeting agents $[3,6]$. Accordingly, a novel approach that reduces toxic effect but reserves the activity to trigger mitotic arrest and cell death can be helpful in cancer chemotherapy.

Aurora A kinase, belonging to a family of mitotic serine/threonine kinase, is implicated with critical processes in cell mitosis [7]. The regulation of Aurora A RNA, protein and kinase activity is dependent of cell cycle with peaking in the transition of G2 to mitotic phase [8]. Aurora A participates in centrosomal separation, formation of bipolar spindle and attachment of chromosomal kinetochore to mitotic spindle [8,9]. Several lines of evidence show that Aurora A is overexpressed in a wide variety of types of cancers, including hepatocellular 
carcinoma, prostate cancer, ovarian cancer and pancreatic cancer [10-12]. Frequent activation/overexpression of Aurora A in human primary prostate cancers has been reported. Furthermore, constitutive Aurora A activation displays higher oncogenic activity $[13,14]$. Activation/overexpression of Aurora A has been suggested to override mitotic spindle assembly checkpoint, leading to the resistance to taxol-induced apoptosis $[3,15]$. Moreover, it overrides cytotoxic agents-mediated downregulation of Bcl-2 and Bcl-xL and decreased NF- $\mathrm{kB}$ activity $[16,17]$, indicating that Aurora A plays a crucial role in addition to cell cycle regulation. These studies suggest that Aurora A can be a potential target for the development of cancer chemotherapeutic drugs.

HRPC occurs when hormone therapy fails to prevent the cancer growth for any longer. Advance prostate cancer often spreads to other parts of the body, including lymph nodes and bones. Therefore, HRPC is a treatment dilemma for practicing physician. Chemotherapy is one of the major choices for HRPC treatment. However, drug resistance developed in cancer cells is always a key concern in cancer chemotherapy. Imidazoles and thiazoles have been widely discovered as fundamental components of structurally diverse natural products that display a variety of activities, such as anticancer and antiviral activities [18-20]. The excellent pharmacological activities based on the azole skeletons have led to the generation of a lot of chemically synthetic compounds and have directed novel therapeutic applications [21]. To search for potential anticancer compounds against HRPCs, we have synthesized a series of derivatives based on thiazoles and imidazoles heterocycles. KUD773, 2-(1H-imidazol-1-yl)-4-(3-(trifluoromethyl)phenyl)thiazole [22], stood out and demonstrated anti-proliferative as well as apoptotic activities in PC-3 and DU-145, two HRPC cell lines. The study has characterized the anticancer activity and the mechanism of action of KUD773. The inhibition of tubulin polymerization and Aurora A activity has been delineated and the downstream signaling cascade has been studied in HRPCs.

\section{Methods}

\section{Materials}

RPMI 1640 medium and fetal bovine serum (FBS) were obtained from GIBCO/BRL Life Technologies (Grand Island, NY). Antibodies to poly ADP ribose polymerase (PARP), caspase-7, Bcl-2, Bak, Bax, Bad, Mcl-1, and anti-mouse and anti-rabbit IgGs were obtained from Santa Cruz Biotechnology, Inc. (Santa Cruz, CA). Antibodies to actin, cyclin B1, cyclin A, caspase-9, caspase-8, phosphorylated cyclin dependent kinase-1 (cdk1) at Tyr15, p-cdk1 $1^{\text {Thr161 }}$, phosphorylated polo-like kinase 1 (PLK1) at Thr210, matrix metalloprotease-2 (MMP-2),

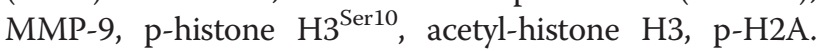

$X^{\text {Ser139 }}(\gamma-$ H2A.X) and GAPDH were from Cell Signaling Technologies (Boston, MA). The antibody to caspase-3 was from Imgenex, Corp. (San Diego, CA). The antibodies to $\beta$-tubulin and mitotic protein monoclonal 2 (MPM-2) were from BD Biosciences PharMingen (San Diego, CA) and Upstate Biotechnology (Lake Placid, NY), respectively. Sulforhodamine B (SRB), taxol, vincristine, carboxyfluorescein succinimidyl ester (CFSE), 4,6-diamidino-2-phenylindole dihydrochloride (DAPI), propidium iodide (PI) and all other chemical compounds were obtained from SigmaAldrich (St. Louis, MO). KUD773 (Figure 1A) was synthesized with the purity of more than $98 \%$ by the examination using ${ }^{1} \mathrm{H}$ and ${ }^{13} \mathrm{C}$ NMR and elemental analysis $(\mathrm{C}, \mathrm{H}, \mathrm{N}, \mathrm{S})[22]$.

\section{Tissue explants and cell culture}

All human tissue samples were obtained following informed consent of the donors and after full review by the Ethics Review Committee at National Taiwan University Hospital. Human prostate specimens were from males by transurethral resection of the prostate in National Taiwan University Hospital. All patients with prostatism histories were diagnosed to have benign prostate hyperplasia by rectal digital examination, transrectal sonography of prostate and urodynamic studies. Isolation of human prostatic cells from prostatic tissue explants was described in the previous study [23]. The HRPC cell lines, PC-3 and DU-145, were obtained from American Type Culture Collection (Rockville, MD). The cells were cultured in RPMI1640 medium with $10 \%$ FBS (v/v) and penicillin (100 units/ml)/streptomycin $(100 \mu \mathrm{g} / \mathrm{ml})$. Cultures were maintained in a humidified incubator at $37^{\circ} \mathrm{C}$ in $5 \%$ $\mathrm{CO}_{2} / 95 \%$ air.

\section{SRB assay}

Cells were seeded in 96-well plates in medium with 5\% FBS. After $24 \mathrm{~h}$, cells were fixed with $10 \%$ trichloroacetic acid (TCA) to represent cell population at the time of compound addition $\left(\mathrm{T}_{0}\right)$. After additional incubation of $0.1 \%$ dimethylsulfoxide (DMSO) or KUD773 for $48 \mathrm{~h}$, cells were fixed with 10\% TCA and SRB at $0.4 \%(\mathrm{w} / \mathrm{v})$ in $1 \%$ acetic acid was added to stain cells. Unbound SRB was washed out by $1 \%$ acetic acid. SRB bound cells were solubilized with $10 \mathrm{mM}$ Trizma base. The absorbance was read at a wavelength of $515 \mathrm{~nm}$. Using the following absorbance measurements, such as time zero $\left(\mathrm{T}_{0}\right)$, control growth (C), and cell growth in the presence of KUD773 (Tx), the percentage growth was calculated at each of the compound concentrations levels. Percentage growth inhibition was calculated as: $\left[1-\left(\mathrm{Tx}-\mathrm{T}_{0}\right) /\left(\mathrm{C}-\mathrm{T}_{0}\right)\right] \times 100 \%$. Growth inhibition of $50 \%\left(\mathrm{GI}_{50}\right)$ is determined at the compound concentration which results in $50 \%$ reduction of total protein increase in control cells during the compound incubation [24]. 

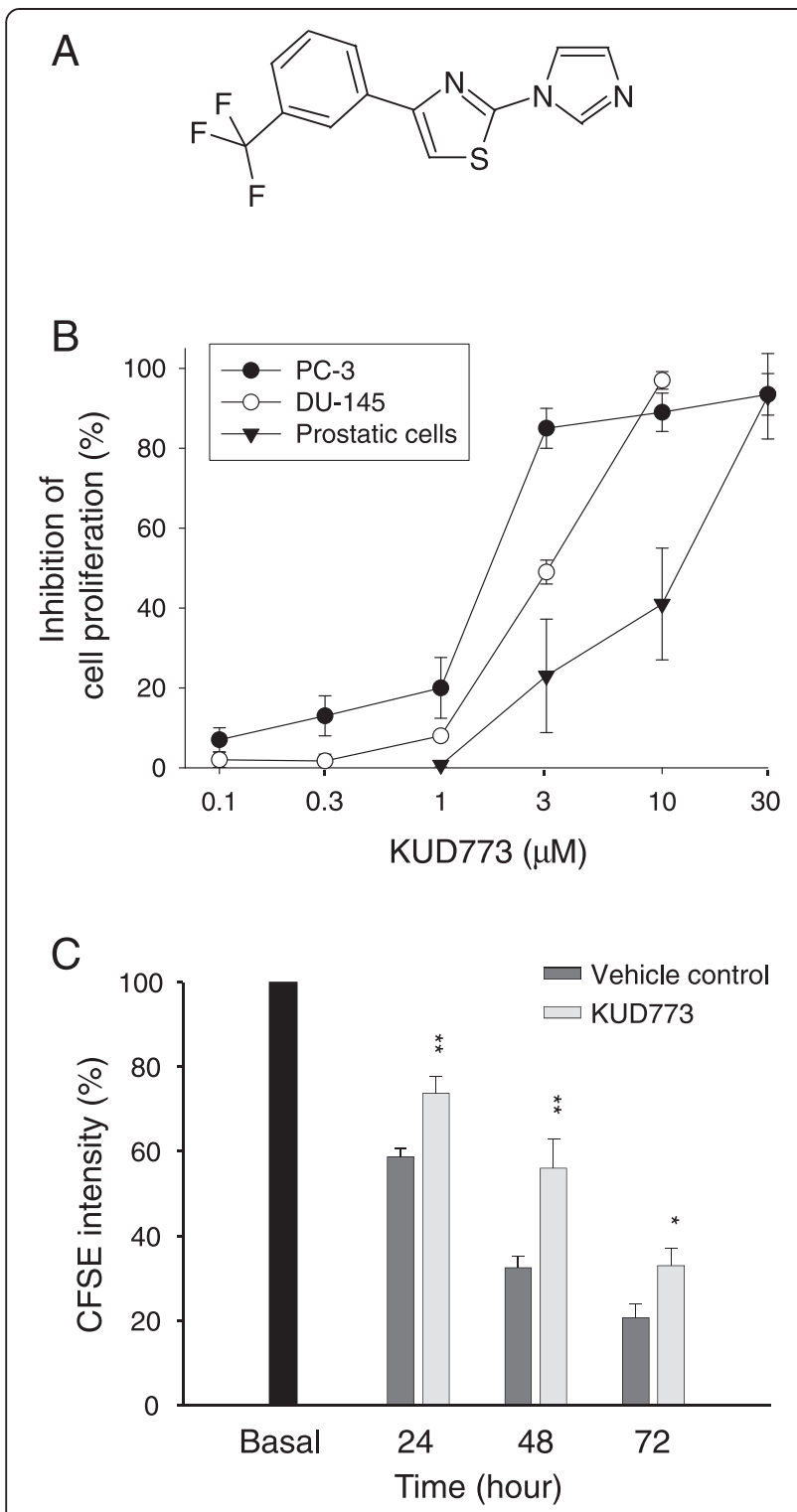

Figure 1 Chemical structure of KUD773 and identification of anti-proliferative effect. (A) Chemical structure of KUD773. (B) After the treatment with or without KUD773 for $48 \mathrm{~h}$, the cells were fixed and stained with SRB and the data were analyzed. (C) PC-3 cells were labeled with CFSE and treated with vehicle or KUD773 (3 $\mu \mathrm{M})$. The fluorescence intensity was determined by flow cytometric analysis. Data are expressed as mean \pm SEM of three determinations. ${ }^{*} P<0.05$ and ${ }^{*} P<0.01$ compared with the respective control.

\section{Cell proliferation assay with CFSE labeling}

The cells were adjusted to a density of $10^{6}$ cells $/ \mathrm{ml}$ and were treated with CFSE at a final concentration of $10 \mu \mathrm{M}$. After incubation at $37^{\circ} \mathrm{C}$ for $10 \mathrm{~min}$, labeling was blocked by the addition of RPMI medium with $10 \%$ FBS. Tubes were placed in ice for $5 \mathrm{~min}$ and then washed. After centrifugation, the cells were seeded in RPMI medium with $10 \%$ FBS for 24,48 and $72 \mathrm{~h}$ at $37^{\circ} \mathrm{C}$ under
$5 \% \mathrm{CO}_{2} / 95 \%$ air. After the treatment, the fluorescence intensity was determined by flow cytometric analysis.

\section{Flow cytometric analysis of PI staining}

After the treatment of cells with vehicle (0.1\% DMSO) or KUD773 for the indicated times, the cells were harvested by trypsinization, fixed with $70 \%(\mathrm{v} / \mathrm{v})$ alcohol at $4^{\circ} \mathrm{C}$ for 30 min and washed with phosphate-buffered saline (PBS). After centrifugation, cells were incubated in $0.1 \mathrm{M}$ of phosphate-citric acid buffer $\left(0.2 \mathrm{M} \mathrm{NaHPO}_{4}, 0.1 \mathrm{M}\right.$ citric acid, $\mathrm{pH} 7.8$ ) for $30 \mathrm{~min}$ at room temperature. Then, the cells were centrifuged and resuspended with $0.5 \mathrm{ml}$ PI solution containing Triton X-100 (0.1\% v/v), RNase (100 $\mu \mathrm{g} / \mathrm{ml})$ and PI $(80 \mu \mathrm{g} / \mathrm{ml})$. DNA content was analyzed with the FACScan and CellQuest software (Becton Dickinson, Mountain View, CA).

\section{Western blotting}

After the indicated exposure time to DMSO or KUD773, the cells were washed twice with ice-cold PBS and reaction was terminated by the addition of $100 \mu$ ice-cold lysis buffer (10 mM Tris- $\mathrm{HCl}, \mathrm{pH} 7.4,150 \mathrm{mM} \mathrm{NaCl}$, $1 \mathrm{mM}$ EGTA, $1 \mathrm{mM}$ phenylmethanesulfonyl fluoride (PMSF), $10 \mu \mathrm{g} / \mathrm{ml}$ aprotinin, $10 \mu \mathrm{g} / \mathrm{ml}$ leupeptin, and $1 \%$ Triton X-100). For western blot analysis, the amount of proteins $(40 \mu \mathrm{g})$ were separated by electrophoresis in a $10 \%$ polyacrylamide gel and transferred to a nitrocellulose membrane. After an overnight incubation at $4^{\circ} \mathrm{C}$ in $\mathrm{PBS} / 5 \%$ nonfat milk, the membrane was washed with PBS/0.1\% Tween 20 for $1 \mathrm{~h}$ and immuno-reacted with the indicated antibody for $2 \mathrm{~h}$ at room temperature. After four washings with PBS/0.1\% Tween 20, the antimouse or anti-rabbit IgG (dilute 1:2000) was applied to the membranes for $1 \mathrm{~h}$ at room temperature. The membranes were washed with PBS/0.1\% Tween 20 for $1 \mathrm{~h}$ and the detection of signal was performed with an enhanced chemiluminescence detection kit (Amersham).

\section{Microtubule assembly assay}

After the treatment with the indicated agent for $24 \mathrm{~h}$, the cells were harvested by trypsinization and collected by centrifugation. The cells were lysed with $0.1 \mathrm{ml}$ of hypotonic buffer (1 mM MgCl $2,2 \mathrm{mM}$ EGTA, 0.5\% NP-40, $2 \mathrm{mM}$ PMSF, $200 \mathrm{U} / \mathrm{ml}$ aprotinin, $100 \mu \mathrm{g} / \mathrm{ml}$ soybean trypsin inhibitor, $5.0 \mathrm{mM} \varepsilon$-amino caproic acid, $1 \mathrm{mM}$ bezamidine and $20 \mathrm{mM}$ Tris- $\mathrm{HCl}, \mathrm{pH}$ 6.8). The cytosolic and cytoskeletal fraction of cell lysate were separated by centrifugation at $16,000 \times \mathrm{g}$ for $15 \mathrm{~min}$. The supernatant contained cytosolic tubulin. The pellet representing the particulate fraction of polymerized tubulin was resuspended in $0.1 \mathrm{ml}$ hypotonic buffer. Tubulin contents in both fractions were detected by Western blotting. 


\section{Confocal immunofluorescence microscopic examination} Cells were seeded in 8-well chamber slides. After the compound treatment for $12 \mathrm{~h}$, the cells were fixed with $100 \%$ methanol at $-20^{\circ} \mathrm{C}$ for $5 \mathrm{~min}$ and incubated in $1 \%$ bovine serum albumin (BSA) containing $0.1 \%$ Triton $\mathrm{X}$ 100 at $37^{\circ} \mathrm{C}$ for $30 \mathrm{~min}$. The cells were washed twice with PBS for 5 min and stained with anti- $\beta$-tubulin or anti- $\gamma$-tubulin antibody at $37^{\circ} \mathrm{C}$ for $1 \mathrm{~h}$ and then, the FITC-conjugated secondary antibody at $37^{\circ} \mathrm{C}$ for $40 \mathrm{~min}$. Nuclear staining was performed by $1 \mu \mathrm{g} / \mathrm{ml}$ DAPI. The cells were analyzed by a confocal laser microscopic system (Leica TCS SP2).

\section{Aurora A luminescent kinase assay}

Test compounds, enzyme and substrate-tetra (LRRWSLG)/ dithiothreitol (DTT)/ATP mix were dissolved in Aur assay buffer $(50 \mathrm{mM}$ Tris- $\mathrm{HCl} \mathrm{pH} 7.4,10 \mathrm{mM} \mathrm{NaCl}$, $10 \mathrm{mM} \mathrm{MgCl}_{2}, 100 \mu \mathrm{g} / \mathrm{ml}$ BSA) separately before the assay. Twenty five $\mu \mathrm{l}$ of test compounds in DMSO stock solution and $10 \mu \mathrm{l}$ enzyme were added into 96 well U-bottomed plate (268152, NUNC, Rochester, NY), and incubated at $25^{\circ} \mathrm{C}$ for $15 \mathrm{~min}$. Fifteen $\mu \mathrm{l}$ substrate/ DTT/ATP mix was added into the plate to initiate the assay. The assays was carried out at $37^{\circ} \mathrm{C}$ for $90 \mathrm{~min}$ in a final volume of $50 \mu \mathrm{l}$ including the following components: $50 \mathrm{mM}$ Tris- $\mathrm{HCl} \mathrm{pH}$ 7.4, $10 \mathrm{mM} \mathrm{NaCl}, 10 \mathrm{mM}$ $\mathrm{MgCl}_{2}, 100 \mu \mathrm{g} / \mathrm{ml} \mathrm{BSA}, 1 \mathrm{mM}$ DTT, $15 \mu \mathrm{M}$ peptide substrate, $5 \mu \mathrm{M}$ ATP, $90 \mathrm{ng} /$ well Aurora A kinase, and test compound. A volume $(50 \mu \mathrm{l})$ of Kinase-Glo Plus Reagent (Promega) was added into the completed kinase reaction, followed by incubation at $25^{\circ} \mathrm{C}$ for $20 \mathrm{~min}$. Seventy $\mu \mathrm{l}$ of reaction mixture was transferred to 96 well black plate and luminescence was recorded by vector2 V (1420 multilable HTS counter, Perkin Elmer, Shelton, CT).

\section{Data analysis}

Data are presented as the mean \pm SEM for the indicated number of separate experiments. Student's $t$-test is applied for comparison of two groups. $P$-values less than 0.05 are statistically considered significant.

\section{Results}

\section{Determination of anti-proliferative activity of KUD773}

The effect of KUD773 on cell proliferation was examined using SRB assay based on the measurement of cellular protein content. The data demonstrated that KUD773 exhibited a higher activity against prostate cancer PC-3 $\left(\mathrm{GI}_{50}=1.7 \mu \mathrm{M}\right)$ and DU-145 $\left(\mathrm{GI}_{50}=3.2 \mu \mathrm{M}\right)$ than primary human prostate cells $\left(\mathrm{GI}_{50}=18.3 \mu \mathrm{M}\right)$ (Figure 1B). The anti-proliferative activity was further confirmed by flow cytometric analysis of CFSE-staining assay. After the conjugation with cellular proteins, CFSE labeling is allocated evenly to daughter cells after cell division. The fluorescence intensity is decreased thereafter.
The data in Figure $1 \mathrm{C}$ demonstrated a doubling time of $30.2 \mathrm{~h}$ in vehicle-treated PC-3 cells. The exposure of KUD773 $(3 \mu \mathrm{M})$ significantly inhibited the decrease of fluorescence intensity showing a doubling time of $53.4 \mathrm{~h}$ (Figure 1C).

\section{Effect of KUD773 on the progression of cell cycle in PC-3 cells}

Cellular stresses may cause the arrest of cell cycle at particular phase, leading to the inhibition of cell proliferation. The effect of KUD773 on the progression of cell cycle was examined by flow cytometric analysis of PI staining with DNA. As a consequence, KUD773 induced an arrest of the cell cycle at G2/M phase in a time-dependent fashion and a subsequent increase of hypodiploid sub-G1 phase (apoptosis) (Figure 2). The progression of cell cycle is regulated by cyclins and the binding partner Cdks. Cyclin A/ Cdk2 complex activity tightly regulates $\mathrm{S}$ phase and G2 phase. In contrast, cyclin B1/Cdk1 complex controls the progression from G2- to M-phase [25]. The exposure of cells to KUD773 resulted in down-regulation of cyclin A while up-regulation of cyclin B1 in PC-3 cells (Figure 3). The effect was associated with an increased phosphorylation of $\mathrm{Cdk} 1$ at $\mathrm{Thr}^{161}$ (a stimulatory phosphorylation site) and a concomitant decreased phosphorylation at $\mathrm{Tyr}^{15}$ (an inhibitory phosphorylation site) (Figure 3), suggesting the activation of Cdk1 [26]. Additionally, the detection of a dramatic increase of mitotic phosphoproteins using antibody to MPM-2 showed that KUD773 induced a mitotic arrest of the cell cycle in PC-3 cells (Figure 3). PLK1 activity, another cell cycle regulator, is altered at different mitotic stages through the phosphorylation at $\mathrm{Thr}^{210}$. The phosphorylation peaks in prometaphase and gradually disappears in anaphase [27]. KUD773 maintained a high level of PLK1 phosphorylation at $\mathrm{Thr}^{210}$ in PC-3 cells (Figure 3 ) indicating that KUD773 induced the mitotic arrest at prometaphase to metaphase. Similar data were also detected in DU-145 cells (Figure 4).

\section{Effect of KUD773 on inhibition of microtubule assembly and formation of monopolar spindle}

Several cellular stresses, including disturbance of microtubule dynamics and inhibition of Aurora A during mitosis, have been suggested to induce mitotic arrest of the cell cycle $[28,29]$. To determine whether tubulin/microtubule served as a target for KUD773, the microtubule assembly assay was performed which the assembly and disassembly microtubules in particulate and soluble fractions, respectively, were separated. As a result, the microtubule assembly (particulate fraction) was decreased in the presence of KUD773 and vincristine (positive control). In contrast, taxol increased the microtubule assembly (Figure 5A). Interestingly, KUD773 induced the formation of monopolar spindle with $12.7 \pm 1.1 \%, 37.8 \pm 6.2 \%$ 

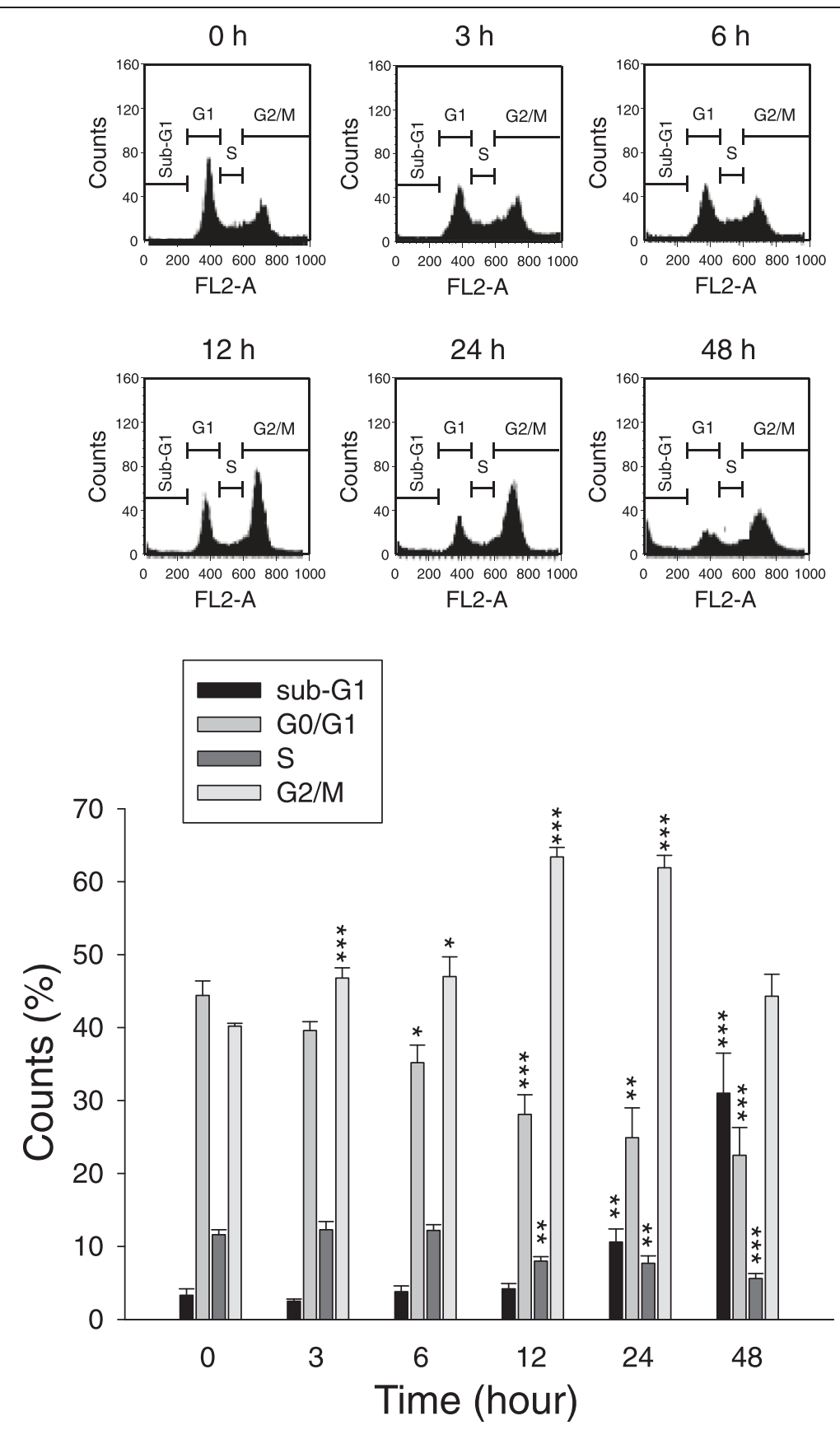

Figure 2 Effect of KUD773 on cell cycle progression and apoptosis. PC-3 cells were treated without or with KUD773 (3 $\mu$ M) for the indicated times. Then, the cells were fixed and stained with PI to analyze DNA content by flow cytometric analysis. Data are expressed as mean \pm SEM of three determinations. ${ }^{*} P<0.05,{ }^{*} P<0.01$ and ${ }^{* *} P<0.001$ compared with the zero time control.

and $51.7 \pm 3.0 \%$, respectively, at 3,10 and $30 \mu \mathrm{M}$ (Figure 5B). The effective concentration for $50 \%$ formation $\left(\mathrm{EC}_{50}\right)$ was $26.2 \mu \mathrm{M}$. The data of $\gamma$-tubulin staining also showed the formation of monopolar spindle (Figure $5 \mathrm{C}$ ). Several lines of evidence reveal that the deficiency of Aurora A activity leads to the failure in centrosomal duplication or centrosomal separation, producing a monopolar spindle array [30,31]. In this study, Aurora A luminescent kinase assay was performed. The data showed that KUD773 inhibited Aurora A in a concentrationdependent manner with an $\mathrm{IC}_{50}$ of $30.0 \mu \mathrm{M}$ (Figure 5D), which was similar to the induction of monopolar spindle formation, indicating that the anti-Aurora A activity might partly contribute to the formation of monopolar spindle. 


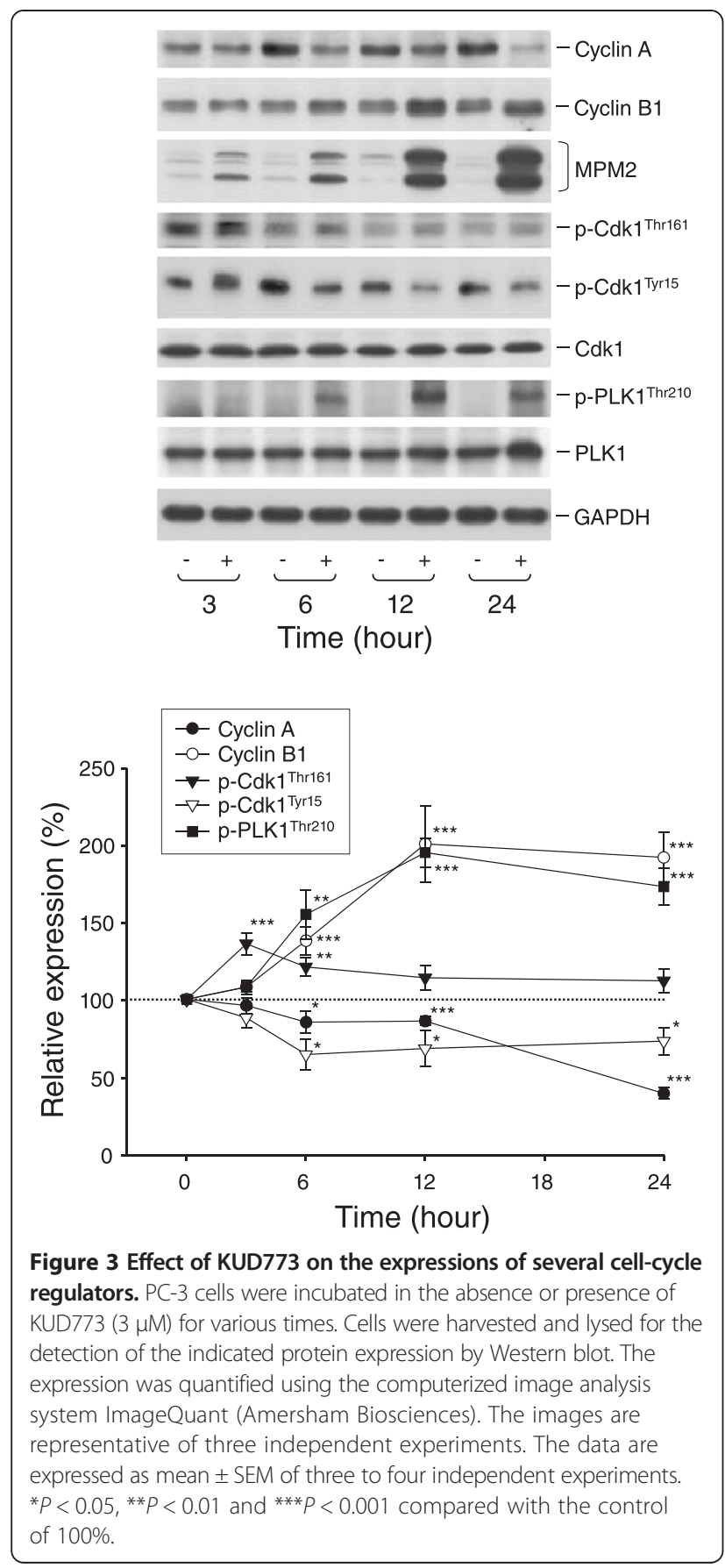

\section{Effect of KUD773 on the expression of Bcl-2 family proteins and caspase cascades}

Bcl-2 family proteins play a central role on regulating the integrity of mitochondrial membrane and caspasemediated apoptotic cell death. Several pro-apoptotic members in this family, including Bax, Bak and Bad, promote the release of cytochrome $c$ and other proteins through the outer mitochondrial membrane. Some members, such as Bcl-2 and Mcl-1, are able to antagonize pro-apoptotic members and to keep mitochondrial integrity $[32,33]$. In

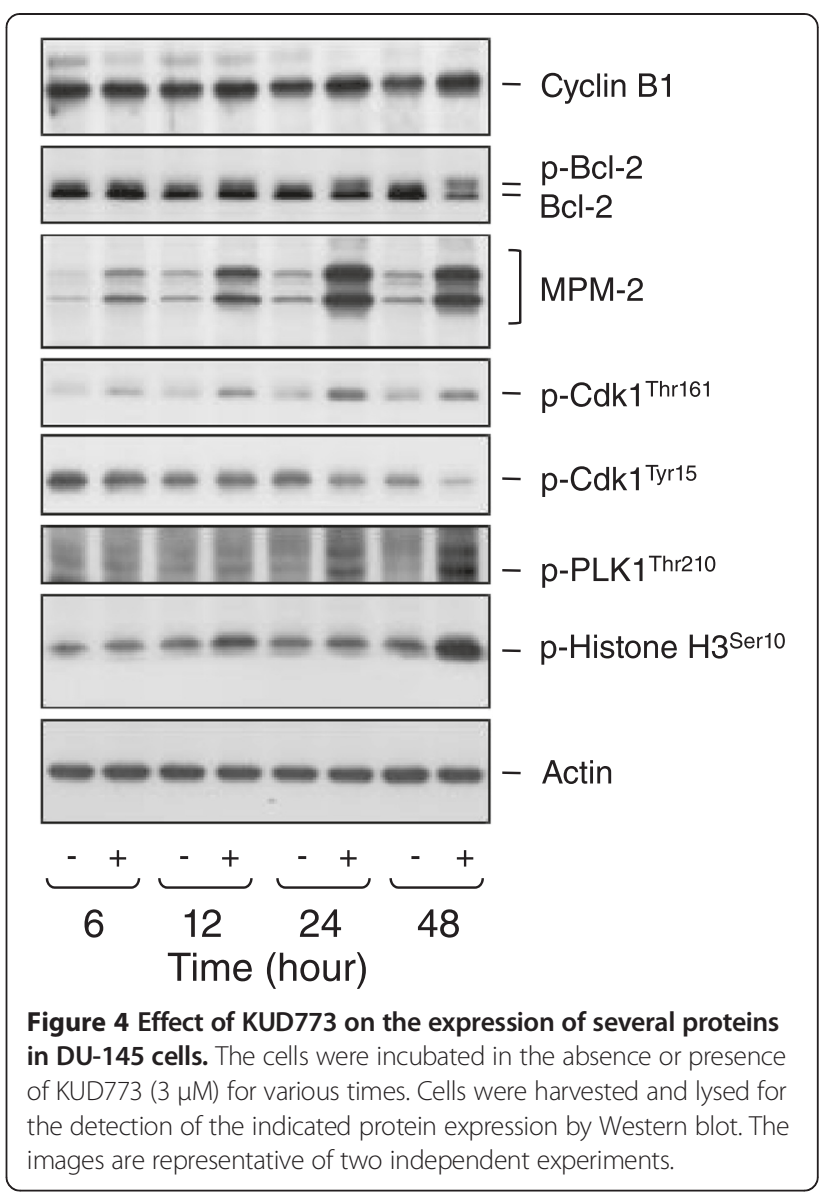

this regard, KUD773 induced a profound increase of Bcl-2 phosphorylation followed by a significant decrease of $\mathrm{Bcl}-$ 2 protein expression in PC-3 cells. In contrast, KUD773 did not modify the protein levels of the other members, including Mcl-1, Bax, Bak and Bad (Figure 6A). Bcl2 phosphorylation, a biochemical marker for tubulintargeting agents [34], also supported that KUD773 acted on tubulin for the execution of anticancer function.

Next, the activation of caspase proteases was examined by Western immunoblot analysis. Caspases were synthesized primarily as inactive precursors. As demonstrated in Figure 6B, the caspases were present as un-cleaved forms in untreated cells. After the exposure to KUD773, the cleavage of inactive precursors to active fragments was detected, in particular, at the 24-h and 48-h treatment. The cleavage of PARP-1, a preferred substrate for caspase-3 and caspase-7, was also apparent to KUD773 action (Figure 6B). The data reveal that the caspase activation is responsible for KUD773-mediated apoptotic cell death.

\section{Effect of KUD773 on the expression levels of MMP-2 and MMP-9}

MMP-2 (gelatinase A) and MMP-9 (gelatinase B) are cancer-associated zinc-dependent endopeptidases. Both 


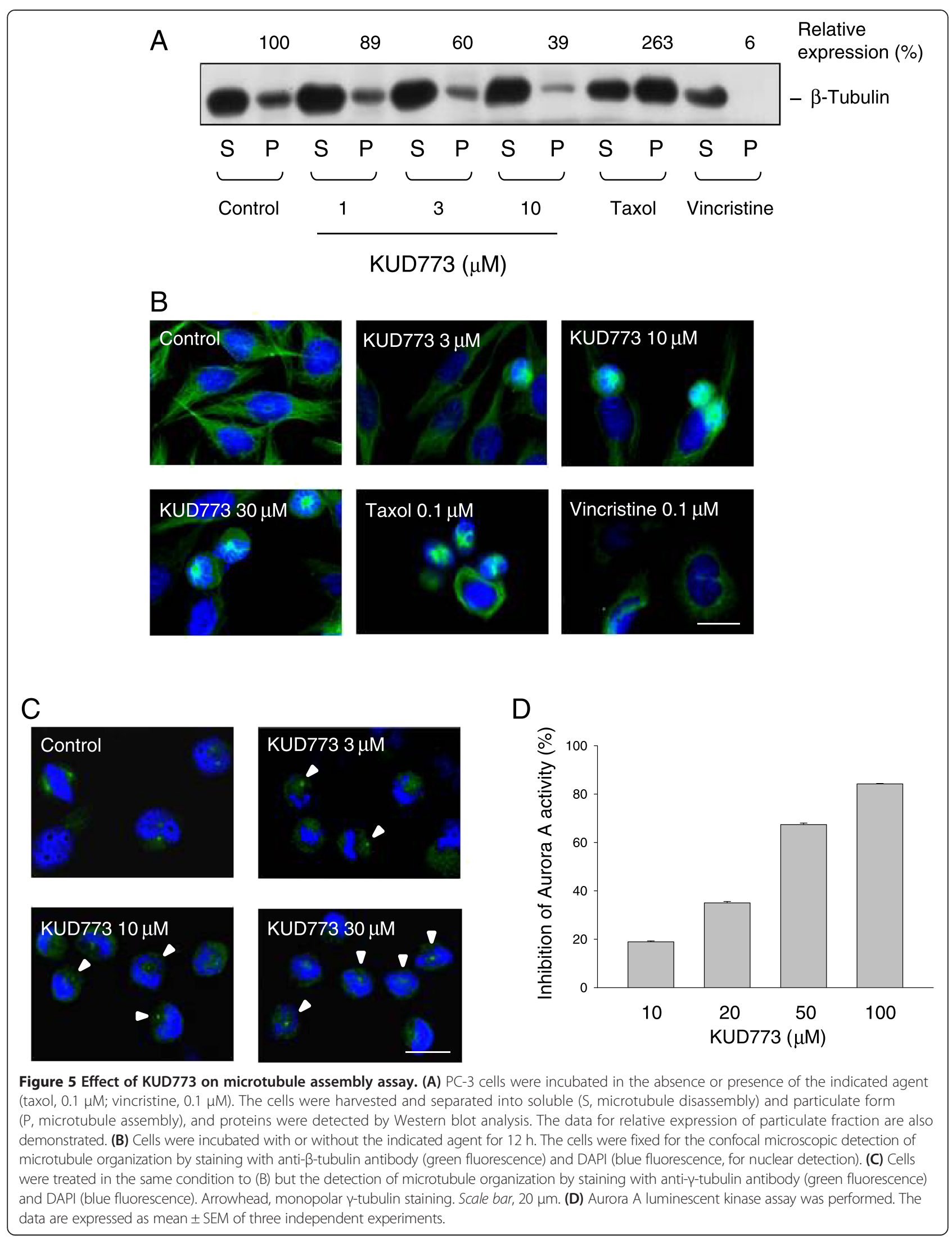




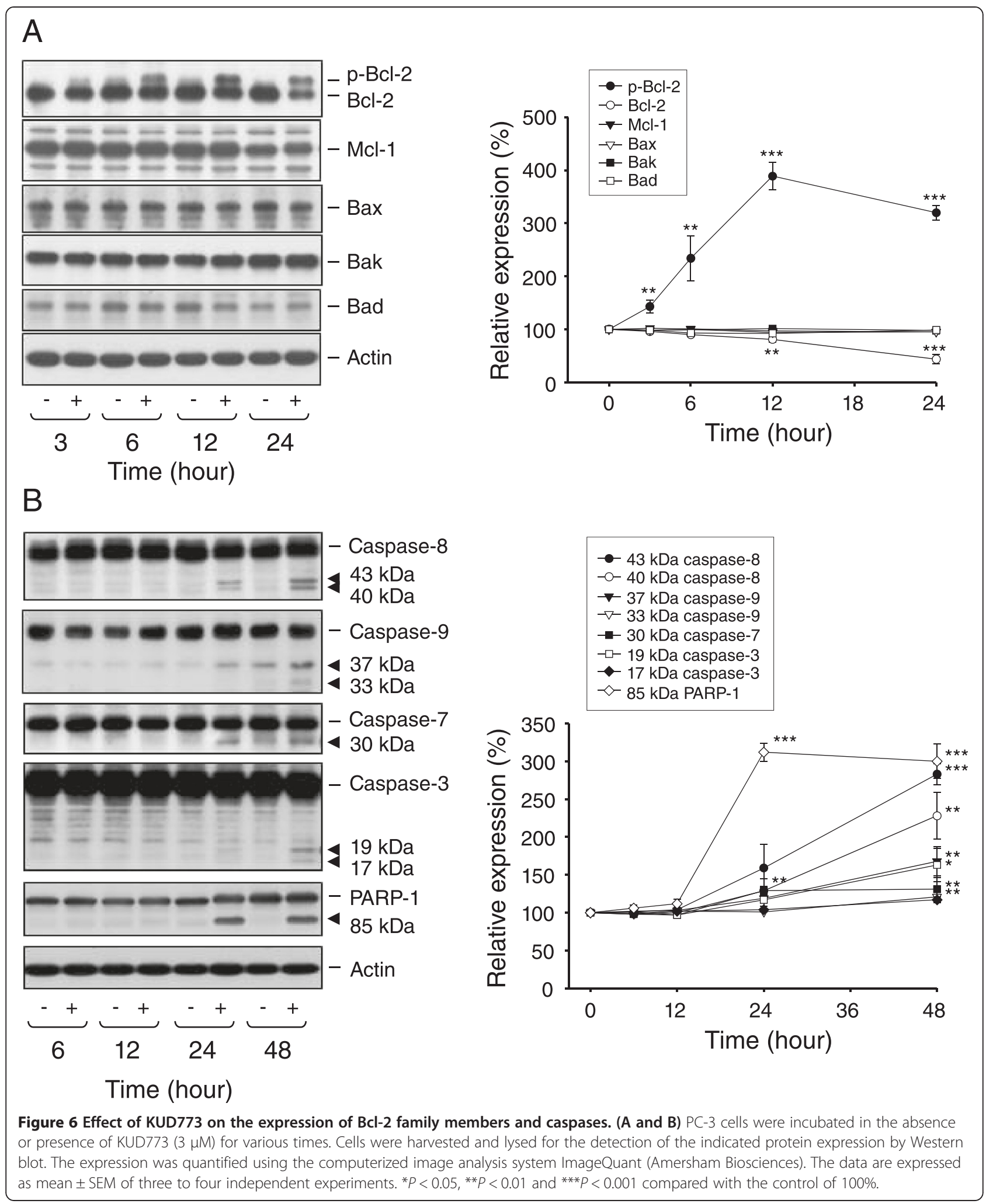

gelatinases play a central role in regulating cell migration, invasion and angiogenesis through cleavage of downstream substrates, including growth factors and their receptors, extracellular matrix and cytokines [35]. Accordingly, development of inhibitors against MMP-2 and MMP-9 is a potential anticancer strategy. In this 
study, KUD773 induced a time-dependent downregulation of MMP-2 and MMP-9 expression. The effect was time-correlated with the increased phosphorylation and acetylation of histone $\mathrm{H} 3$ (two responses in mitosis), but was prior to the production of $\gamma$-H2A.X (a DNA damage response) (Figure 7A). The data indicated that the decreased expression of MMP-2 and MMP-9 was related to the mechanism of mitotic arrest but not through the DNA-damaged cell death because both camptothecin and etoposide (two topoisomerase poisons) which could induce DNA damage and cell death did not result in the down-regulation of MMP-2 and MMP-9 (Figure 7B).

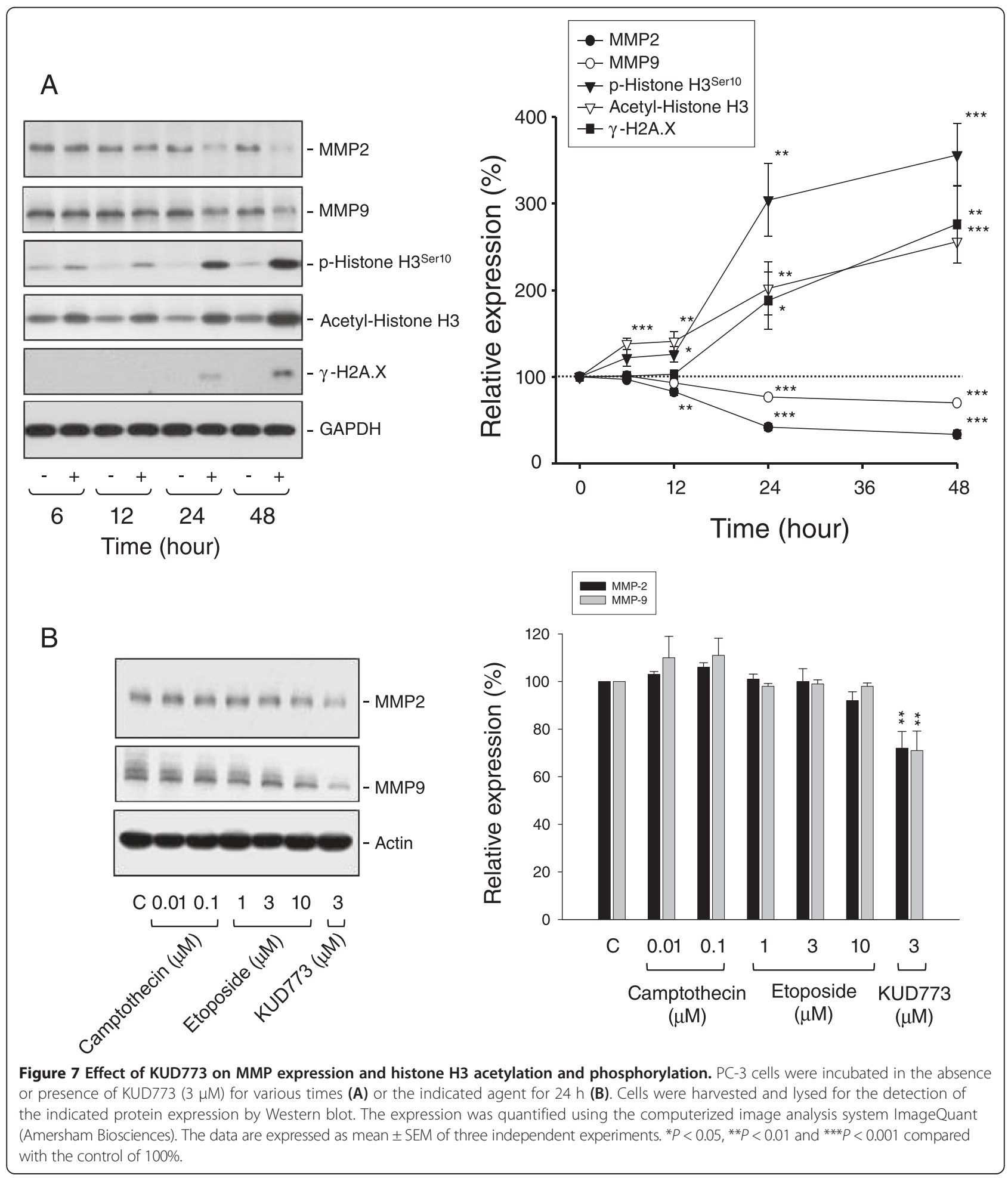




\section{Discussion}

Tubulin-targeting agents have long been used for clinical cancer chemotherapy against a wide variety of cancers. However, the mechanism-related toxicity, such as peripheral neuropathy, limits the therapeutic use of these agents $[3,6]$. The present study seeks to solve the problem by developing novel agents of introducing antiAurora A activity into anti-tubulin agents. The rationale is based on the strategy that mitotic interrupting agents always display high selectivity between cancer cells and normal cells $[3,4,9,36]$. Both tubulin-targeting and antiAurora A agents are mitotic interrupting agents. Furthermore, dual-effect inhibitors may reserve individual activities while decrease the toxicity because of the reduced concentrations used for reaching similar efficacy. The flow cytometric analysis of PI staining showed that KUD773 induced G2/M arrest of the cell cycle and a subsequent cell apoptosis. The data together with the dramatic increase of mitotic protein phosphorylation indicated the mitotic arrest other than G2 arrest to KUD773 action. The cell-based microtubule assembly assay showed that KUD773, similar to vincristine, inhibited tubulin polymerization and microtubule assembly. The SRB assay also has been performed to examine the effect of KUD773 on anti-proliferation in several cancer cell lines. The $\mathrm{GI}_{50}$ values were 2.2, 2.3, 2.1 and 5.2 in MDA-MB-231 (breast cancer), A549 (non-small cell lung cancer), HCT-116 (colorectal cancer) and HT-29 (colorectal cancer), respectively. It is not surprising that KUD773 is effective against all tested cancer cell lines because the action target on tubulin is universal in cells, in particular in proliferating cancer cells.

KUD773 induced a significant increase of Bcl-2 phosphorylation, a specific hallmark to tubulin-targeting agents [37]. It has been suggested that phosphorylated Bcl-2 fails to dimerize with Bax, leading to augmented levels of free Bax and acceleration of cell apoptosis [38]. Several studies show that Bcl-2 may bind Raf- 1 . Furthermore, Raf- 1 depletion by geldanamycin inhibits Bcl-2 phosphorylation $[37,39,40]$, suggesting that Raf- 1 is a potential candidate for Bcl-2 phosphorylation. However, the responsible kinase for KUD773-mediated Bcl-2 phosphorylation needs further investigation.

Cdk1 interacts with cyclin B1 to form a heterodimer complex. The complex activity is required for the progression of cell cycle to mitotic prophase and metaphase. Moreover, it has been identified that Cdk1 activity is responsible for triggering cell death in certain signaling cascades under apoptotic stimuli, including exposure to tubulin-targeting agents $[9,36,37]$. The entry of cell cycle into mitosis is controlled by Cdk1 activation through several steps, including cyclin B1 binding and Cdk1 phosphorylation at $\mathrm{Thr}^{161}$. Moreover, dephosphorylation of Cdk1 at $\mathrm{Tyr}^{15}$ appears to be a critical step for Cdk1 activation during the progression into cell mitosis [25,41]. The data showed that KUD773 induced the activation of Cdk1 and mitotic arrest in both PC- 3 and DU145 cells. These events could guarantee the activation of apoptotic program because it has been extensively identified that premature activation of Cdk1 can result in mitotic catastrophe after a wide variety of cellular stresses $[9,26,42]$.

The Aurora kinases, including Aurora A, Aurora B and Aurora $\mathrm{C}$, are serine/threonine kinases that are implicated with critical processes in cell mitosis [7]. Aurora A, an oncogenic Aurora kinase, is mainly centrosomal and localizes to mitotic spindle. It is necessary for centrosome separation and microtubule assembly $[8,9]$. Aurora B has been shown to colocalize with end-binding protein 1 on central spindle during anaphase and on midbody during cytokinesis, playing a crucial role in chromosome biorientation, cytokinesis and spindle assembly checkpoint $[43,44]$. By contrast, much less is known about the cellular function of Aurora C. However, recent studies show that overexpression of active Aurora $\mathrm{C}$ in NIH-3T3 stable cell lines leads to tumor formation when injected into nude mice, showing an oncogenic activity of active Aurora C [45]. The present data demonstrated that KUD773 displayed an inhibitory activity against Aurora A using luminescent kinase assay. The inhibitory activity was further validated by the observation that KUD773 induced the formation of monopolar spindle because Aurora A was responsible for centrosome separation. The effect was similar to other Aurora A inhibitors, such as VX-680 that led to monopolar spindle formation in a wide variety of cancer cells [46]. Of note, KUD773 caused histone H3 phosphorylation at $\mathrm{Ser}^{10}$. It has been documented that both Aurora $A$ and Aurora B are able to phosphorylate histone H3 [47]. However, Aurora B is specifically responsible for the phosphorylation of histone $\mathrm{H} 3$ not only at $\mathrm{Ser}^{10}$ but also at $\mathrm{Ser}^{28}$ that contribute to mitotic chromosome condensation $[44,47,48]$. KUD773 showed effective inhibition on Aurora A but not Aurora B (data not shown), explaining that histone $\mathrm{H} 3$ phosphorylation still occurred during KUD773-induced mitotic arrest.

MMPs, zinc-dependent endopeptidases, are capable of degrading a wide spectrum of extracellular matrix proteins. MMPs are also involved in proteolysis of many non-matrix substrates, such as cytokines and chemokines [49]. Recently, MMP activity has been known to play a key role in the cleavage of Fas, leading to an increased resistance to FasL-mediated apoptosis in various cancer cells [50]. MMPs are, therefore, thought to play a crucial role on directing several cell functions, such as cell migration, proliferation, differentiation, apoptosis and angiogenesis [35,49]. Among this family of members, MMP-2 and MMP-9 have been characterized as 
crucial factors contributing to angiogenesis and tumor invasion [35]. Moreover, highly metastatic variants of prostate cancers are revealed to contain relatively high levels of MMP-2 and MMP-9 [51]. The present study demonstrated that KUD773 induced a significant downregulation of MMP-2 and MMP-9 expression, suggesting an anti-metastatic potential of KUD773 although this effect has not been determined in this study. The data also revealed that the inhibitory effect on MMP expression levels was related to KUD773-mediated anti-mitotic activity. It has been suggested that inhibition of tubulin polymerization may cause the suppression of genetic transcription and mRNA instability of both MMP-2 and MMP-9 [52]. It may explain KUD773-induced downregulation of these two MMP members. However, the underlying mechanism warrants further investigation.

\section{Conclusions}

The data suggest that KUD773 induces apoptotic signaling in a sequential manner. It inhibits tubulin polymerization associated with an anti-Aurora A activity, leading to Cdk1 activation and mitotic arrest of the cell cycle that in turn induces Bcl-2 degradation and a subsequent caspase activation in HRPCs. The inhibitory activity on the expression of MMP-2 and MMP-9 may add the anticancer potential of KUD773. Because the class of compounds with imidazole or thiazole structure has been reported to display some other activities, such as inhibition of Akt, p38 MAPK and tyrosine kinase, the anticancer effect of KUD773 may also attributed to other undefined mechanisms that warrant further elucidation. However, KUD773 which displays both antitubulin and anti-Aurora A activities is a novel design for dual-effect inhibitors although its structure needs further optimization for activity improvement.

\section{Competing interests}

The authors declare that they have no competing interests.

\section{Authors' contributions}

CCY carried out all the experiments except for Aurora A luminescent kinase assay and primary cell culture from human prostate specimens. SPL participated project design and provided human prostate specimens, JLH performed primary cell culture from human prostate specimens. JTAH performed Aurora A luminescent kinase assay, KVK synthesized KUD773 and provided the compound and JHG supervised experimental design, data analysis and reviewed manuscript. All authors have read and approved the final manuscript.

\section{Acknowledgements \\ We acknowledge the support provided by the National Science Council of the Republic of China (NSC101-2923-B-002-008-MY3) and the Russian Foundation for Basic Research (project No. 12-03-92005-HHC-a), M.V. Lomonosov Moscow State University Program of Development and RAS Programme OXHM 9 "Medicinal Chemistry". The support by the Center for Innovative Therapeutics Discovery at National Taiwan University is also acknowledged.}

\section{Author details}

${ }^{1}$ School of Pharmacy, National Taiwan University, Taipei, Taiwan.

${ }^{2}$ Department of Urology, National Taiwan University Hospital, Taipei, Taiwan.
${ }^{3}$ Institute of Biotechnology and Pharmaceutical Research, National Health Research Institutes, Zhunan, Taiwan. ${ }^{4}$ Department of Medicinal Chemistry, Faculty of Chemistry, M.V. Lomonosov Moscow State University, Moscow, Russian Federation. ${ }^{5}$ nstitute of Physiologically Active Compounds, Russian Academy of Sciences, Moscow region, Russian Federation.

Received: 24 August 2014 Accepted: 17 December 2014 Published online: 07 January 2015

\section{References}

1. Martin SK, Kamelgarn M, Kyprianou N. Cytoskeleton targeting value in prostate cancer treatment. Am J Clin Exp Urol. 2014;2:15-26.

2. Martínez-Díez M, Guillén-Navarro MJ, Pera B, Bouchet BP, Martínez-Leal JF, Barasoain I, et al. PM060184, a new tubulin binding agent with potent antitumor activity including P-glycoprotein over-expressing tumors. Biochem Pharmacol. 2014;88:291-302.

3. Schmidt M, Bastians H. Mitotic drug targets and the development of novel anti-mitotic anticancer drugs. Drug Resist Updat. 2007;10:162-81.

4. Mekhail TM, Markman M. Paclitaxel in cancer therapy. Expert Opin Pharmacother. 2002;3:755-66.

5. Khan MA, Carducci MA, Partin AW. The evolving role of docetaxel in the management of androgen independent prostate cancer. J Urol. 2003;170:1709-16.

6. Marupudi NI, Han JE, Li KW, Renard VM, Tyler BM, Brem H. Paclitaxel: a review of adverse toxicities and novel delivery strategies. Expert Opin Drug Saf. 2007:6:609-21.

7. Walter AO, Seghezzi W, Korver W, Sheung J, Lees E. The mitotic serine/ threonine kinase Aurora2/AIK is regulated by phosphorylation and degradation. Oncogene. 2000;19:4906-16.

8. Bischoff JR, Plowman GD. The Aurora//pl1p kinase family: regulators of chromosome segregation and cytokinesis. Trends Cell Biol. 1999;9:454-9.

9. Bhalla KN. Microtubule-targeted anticancer agents and apoptosis. Oncogene. 2003;22:9075-86.

10. Jeng YM, Peng SY, Lin CY, Hsu HC. Overexpression and amplification of Aurora-A in hepatocellular carcinoma. Clin Cancer Res. 2004;10:2065-71.

11. Han H, Bearss DJ, Browne LW, Calaluce R, Nagle RB, Von Hoff DD. Identification of differentially expressed genes in pancreatic cancer cells using CDNA microarray. Cancer Res. 2002;62:2890-6.

12. Matarasso N, Bar-Shira A, Rozovski U, Rosner S, Orr-Urtreger A. Functional analysis of the Aurora Kinase A lle31 allelic variant in human prostate. Neoplasia. 2007;9:707-15.

13. Lee EC, Frolov A, Li R, Ayala G, Greenberg NM. Targeting Aurora kinases for the treatment of prostate cancer. Cancer Res. 2006;66:4996-5002.

14. Bar-Shira A, Pinthus JH, Rozovsky U, Goldstein M, Sellers WR, Yaron Y, et al. Multiple genes in human 20913 chromosomal region are involved in an advanced prostate cancer xenograft. Cancer Res. 2002;62:6803-7.

15. Anand S, Penrhyn-Lowe S, Venkitaraman AR. Aurora-A amplification overrides the mitotic spindle assembly checkpoint, inducing resistance to Taxol. Cancer Cell. 2003;3:51-62.

16. Cammareri P, Scopelliti A, Todaro M, Eterno V, Francescangeli F, Moyer MP, et al. Aurora-A is essential for the tumorigenic capacity and chemoresistance of colorectal cancer stem cells. Cancer Res. 2010;70:4655-65.

17. Sun C, Chan F, Briassouli P, Linardopoulos S. Aurora kinase inhibition downregulates NF-kappaB and sensitises tumour cells to chemotherapeutic agents. Biochem Biophys Res Commun. 2007;352:220-5.

18. Uemoto H, Yahiro Y, Shigemori H, Tsuda M, Takao T, Shimonishi Y, et al. Keramamides $\mathrm{K}$ and $\mathrm{L}$, new cyclic peptides containing unusual tryptophan residue from Theonella sponge. Tetrahedron. 1998:54:6719-24.

19. Li CM, Chen J, Lu Y, Narayanan R, Parke DN, Li W, et al. Pharmacokinetic optimization of 4-substituted methoxybenzoyl-aryl-thiazole and 2-aryl-4benzoyl-imidazole for improving oral bioavailability. Drug Metab Dispos. 2011;39:1833-9.

20. Andreani A, Granaiola M, Leoni A, Locatelli A, Morigi R, Rambaldi M, et al. Potential antitumor agents. 37. Synthesis and antitumor activity of guanylhydrazones from imidazo[2,1-b]thiazolesand from the new heterocyclic system thiazolo[2',3':2,3]imidazo[4,5-c]quinoline. J Med Chem. 2005;48:3085-9.

21. Andreani A, Granaiola M, Locatelli A, Morigi R, Rambaldi M, Varoli L, et al. Substituted 3-(5-imidazo[2,1-b]thiazolylmethylene)- 2-indolinones and analogues: synthesis, cytotoxic activity, and study of the mechanism of action. J Med Chem. 2012;55:2078-88. 
22. Kudryavtsev KV, Churakov AV, Guh JH. 2-(1H-Imidazol-1-yl)- 4-[3-(trifluoromethyl) phenyl]-1,3-thiazole. Acta Cryst. 2013;E69:0238.

23. Guh JH, Hwang TL, Ko FN, Chueh SC, Lai MK, Teng CM. Antiproliferative effect in human prostatic smooth muscle cells by nitric oxide donor. Mol Pharmacol. 1998;53:467-74.

24. Skehan P, Storeng R, Scudiero D, Monks A, McMahon J, Vistica D, et al. New colorimetric cytotoxicity assay for anticancer-drug screening. J Natl Cancer Inst. 1990;82:1107-12.

25. Vermeulen K, Van Bockstaele DR, Berneman ZN. The cell cycle: a review of regulation, deregulation and therapeutic targets in cancer. Cell Prolif. 2003;36:131-49.

26. Castedo M, Perfettini JL, Roumier T, Andreau K, Medema R, Kroemer G. Cell death by mitotic catastrophe: a molecular definition. Oncogene. 2004;23:2825-37.

27. Golsteyn RM, Mundt KE, Fry AM, Nigg EA. Cell cycle regulation of the activity and subcellular localization of Plk1, a human protein kinase implicated in mitotic spindle function. J Cell Biol. 1995;129:1617-28.

28. Lens SM, Voest EE, Medema RH. Shared and separate functions of polo-like kinases and aurora kinases in cancer. Nat Rev Cancer. 2010;10:825-41.

29. Sarkar T, Nguyen TL, Su ZW, Hao H, Bai R, Gussio R, et al. Interaction of pseudolaric acid B with the colchicine site of tubulin. Biochem Pharmacol. 2012;84:444-50.

30. Cowley DO, Rivera-Pérez JA, Schliekelman M, He YJ, Oliver TG, Lu L, et al. Aurora-A kinase is essential for bipolar spindle formation and early development. Mol Cell Biol. 2009;29:1059-71.

31. Liu Q, Ruderman JV. Aurora A, mitotic entry, and spindle bipolarity. Proc Natl Acad Sci U S A. 2006;103:5811-6.

32. Adams JM, Cory S. The Bcl-2 apoptotic switch in cancer development and therapy. Oncogene. 2007;26:1324-37.

33. Cleland MM, Norris KL, Karbowski M, Wang C, Suen DF, Jiao S, et al. BCl-2 family interaction with the mitochondrial morphogenesis machinery. Cell Death Differ. 2011;18:235-47.

34. Mellor HR, Rouschop KM, Wigfield SM, Wouters BG, Harris AL. Synchronised phosphorylation of BNIP3, BCl-2 and BCl-xL in response to microtubule-active drugs is JNK-independent and requires a mitotic kinase. Biochem Pharmacol. 2010;79:1562-72.

35. Bauvois B. New facets of matrix metalloproteinases MMP-2 and MMP-9 as cell surface transducers: outside-in signaling and relationship to tumor progression. Biochim Biophys Acta. 1825;2012:29-36.

36. Chang WL, Chang CS, Chiang PC, Ho YF, Liu JF, Chang KW, et al. 2-Phenyl5-(pyrrolidin-1-yl)-1-(3,4,5-trimethoxybenzyl)-1H-benzimidazole, a benzimidazole derivative, inhibits growth of human prostate cancer cells by affecting tubulin and c-Jun N-terminal kinase. Br J Pharmacol. 2010;160:1677-89.

37. Blagosklonny MV, Fojo T. Molecular effects of paclitaxel: myths and reality (a critical review). Int J Cancer. 1999;83:151-6.

38. Haldar $\mathrm{S}$, Jena N, Croce CM. Inactivation of $\mathrm{BCl}-2$ by phosphorylation. Proc Natl Acad Sci U S A. 1995;92:4507-11.

39. Blagosklonny MV, Schulte TW, Nguyen P, Trepel J, Neckers L. Taxol-induced apoptosis and phosphorylation of BCl-2 protein involves c-raf-1 and represents a novel c-Raf-1 signal transduction pathway. Cancer Res. 1996;56:1851-4.

40. Torres K, Horwitz SB. Mechanisms of Taxol-induced cell death are concentration dependent. Cancer Res. 1998:58:3620-6.

41. Norbury C, Blow J, Nurse P. Regulatory phosphorylation of the p34cdc2 protein kinase in vertebrates. EMBO J. 1991;10:3321-9.

42. Castedo M, Perfettini JL, Roumier T, Kroemer G. Cyclin-dependent kinase-1: linking apoptosis to cell cycle and mitotic catastrophe. Cell Death Differ. 2002;9:1287-93.

43. Harrison MR, Holen KD, Liu G. Beyond taxanes: a review of novel agents that target mitotic tubulin and microtubules, kinases, and kinesins. Clin Adv Hematol Oncol. 2009;7:54-64.

44. Adams RR, Maiato H, Earnshaw WC, Carmena M. Essential roles of Drosophila inner centromere protein (INCENP) and Aurora-B in histone $\mathrm{H} 3$ phosphorylation, metaphase chromosome alignment, kinetochore disjunction, and chromosome segregation. J Cell Biol. 2001;153:865-80

45. Khan J, Ezan F, Crémet JY, Fautrel A, Gilot D, Lambert M, et al. Overexpression of active Aurora-C kinase results in cell transformation and tumour formation. PLoS One. 2011;6:e26512.

46. Tyler RK, Shpiro N, Marquez R, Eyers PA. VX-680 inhibits Aurora A and Aurora B kinase activity in human cells. Cell Cycle. 2007;6:2846-54.
47. Crosio C, Fimia GM, Loury R, Kimura M, Okano Y, Zhou H, et al. Mitotic phosphorylation of histone $\mathrm{H} 3$ : spatio-temporal regulation by mammalian Aurora kinases. Mol Cell Biol. 2002;22:874-85.

48. Goto H, Yasui Y, Nigg EA, Inagaki M. Aurora-B phosphorylates histone H3 at serine28 with regard to the mitotic chromosome condensation. Genes Cells. 2002;7:11-7.

49. Van Lint $P$, Libert $C$. Chemokine and cytokine processing by matrix metalloproteinases and its effect on leukocyte migration and inflammation. J Leukoc Biol. 2007;82:1375-81.

50. Wang WS, Chen PM, Wang HS, Liang WY, Su Y. Matrix metalloproteinase-7 increases resistance to Fas-mediated apoptosis and is a poor prognostic factor of patients with colorectal carcinoma. Carcinogenesis. 2006;27:1113-20.

51. Aalinkeel R, Nair BB, Reynolds JL, Sykes DE, Mahajan SD, Chadha KC, et al. Overexpression of MMP-9 contributes to invasiveness of prostate cancer cell line LNCaP. Immunol Invest. 2011;40:447-64.

52. Liu WH, Chen YL, Chang LS. CIL-102 induces matrix metalloproteinase-2 (MMP-2)/MMP-9 down-regulation via simultaneous suppression of genetic transcription and mRNA stability. Int J Biochem Cell Biol. 2012;44:2212-22.

\section{Submit your next manuscript to BioMed Central and take full advantage of:}

- Convenient online submission

- Thorough peer review

- No space constraints or color figure charges

- Immediate publication on acceptance

- Inclusion in PubMed, CAS, Scopus and Google Scholar

- Research which is freely available for redistribution 